\title{
A poluição visual e seus impactos no espaço urbano em Palmas- TO: uma década de transformação
}

\section{Visual pollution and its impacts on urban space in Palmas-TO: a decade of transformation}

DOI: $10.46814 /$ lajdv3n5-013

Recebimento dos originais: 01/05/2021

Aceitação para publicação: 31/06/2021

\author{
Hareli Fernanda Garcia Cecchin \\ Psicóloga (CRP23-743), Mestre em Desenvolvimento Regional (UFT) \\ Instituição de atuação atual: Universidade Federal do Tocantins \\ E-mail: hareli@uft.edu.br / harelifernanda@gmail.com \\ Irenides Teixeira \\ Psicóloga (CRP23-463), Doutora em Educação (UFBA) \\ Instituição de atuação atual: Centro Universitário Luterano de Palmas - Ceulp/Ulbra \\ E-mail: irenides@gmail.com
}

\begin{abstract}
RESUMO
A poluição visual é um fenômeno que deve ser discutido, visto que afeta diretamente a qualidade de vida do cidadão, a paisagem e a memória urbana. $\mathrm{O}$ objetivo da pesquisa foi mapear a poluição visual, no espaço urbano, em Palmas-TO e comparar com a poluição visual existente em 2010. O estudo foi realizado por meio de registro fotográfico das peças publicitárias presentes nas 10 quadras do centro simbólico, em localidades de maior concentração de mídia externa. Os resultados apontam que outdoors de madeira e de metal, pequenas placas e faixas foram retiradas. Em algumas localidades onde o poder público conseguiu retirar os outdoors, a iniciativa privada incorporou a publicidade a sua estrutura predial. Os outdoors de metal sem anúncio continuam sendo uma problemática ainda não resolvida na cidade. Não foram encontrados painéis digitais nas localidades monitoradas. Ao longo dos 11 anos de comparação observou-se maior fiscalização por parte dos órgãos públicos. Aos gestores públicos e a sociedade civil sugere-se o contínuo monitoramento da poluição visual. Aos pesquisadores sugere-se estudos que considerem a influência da poluição visual nas ocorrências de acidentes de trânsito. O estudo permitiu uma reflexão do contexto histórico recente da cidade de Palmas-TO.
\end{abstract}

Palavras-chave: comunicação visual, publicidade e propaganda, poluição visual, espaço urbano.

\begin{abstract}
Visual pollution is a phenomenon that should be discussed, as it directly affects the quality of life of citizens, the landscape and urban memory. The objective of the research was to map the visual pollution in urban spaces in Palmas-TO and compare it with the existing visual pollution in 2010 and 2021. The study was carried out through a photographic record of advertising pieces present in the 10 blocks of the symbolic center, in locations with a higher concentration of external media. The results show that wooden and metal billboards, small signs and banners were removed. In some places where the government managed to remove the billboards, the private sector incorporated advertising into its building structure. Ad-free metal billboards remain an unresolved issue in the city. No digital panels were found in the monitored locations. Over the 11 years of comparison, greater inspection by public bodies was observed. Public managers and civil society are encouraged to continuously monitor visual
\end{abstract}


pollution. Researchers are encouraged to carry out studies that consider the influence of visual pollution on the occurrence of traffic accidents. The study allowed a reflection on the recent historical context of the city of Palmas-TO.

Keywords: visual communication, advertising and marketing, visual pollution, urban space.

\section{INTRODUÇÃO}

A problemática do caos visual ganhou relevância nas últimas décadas, atraindo profissionais de diversas áreas do conhecimento em encontros e debates, pois se trata de um fenômeno observado principalmente nos grandes centros urbanos. Segundo o primeiro tratado internacional a respeito do tema, a Convenção Europeia da Paisagem (European Landscape Convention), a poluição visual é considerada uma degradação da paisagem devido ao acúmulo de instalações (torres, cartazes de propaganda, anúncios ou qualquer outro material publicitário) ou da presença de vegetação ou projetos construtivos inadequados ou mal localizados (CASTANHEIRO, 2009).

Estudos e observações apontam que ambientes marcados por uma profusão de anúncios publicitários, além de dificultar a percepção dos espaços da cidade (castanheiro, 2009), levam os indivíduos a distração, fadiga visual e estresse (PINHEIRO, 2004) por conta do excesso de informação. Essas consequências influenciam não só os pedestres, mas também os condutores de veículos e motocicletas, contribuindo para o aumento dos acidentes de trânsito.

Isto contribuiu para que os efeitos nocivos da propaganda e da publicidade ganhassem a atenção da sociedade, sobretudo pela sua influência na paisagem e no bem-estar da população. Ao entrar para a pauta das discussões ambientais, a poluição visual começou a ser levada em conta, ganhando disposições na Constituição Brasileira de 1988 e no Código Nacional de Trânsito. No entanto, percebemos que estas normas jurídicas são insuficientes e há uma necessidade de estudos para avaliar o impacto da poluição visual nos diferentes âmbitos sociais, sobretudo no trânsito.

Em 2008, Palmas, capital do estado do Tocantins, ocupava o segundo lugar no ranking de acidentes de trânsito (BRASIL, 2009). Apesar dos investimentos em equipamentos de fiscalização, sinalização e programas educativos (PEREIRA, 2018), a cidade ainda tem um dos trânsitos mais inseguros do país, com aumento de 27\% na taxa de mortalidade de 2011 a 2019 (FERNANDA, 2019). Determinadas caraterísticas da cidade como o relevo plano e as avenidas largas e planejadas pode contribuir para o desrespeito dos limites de velocidade.

\section{COMUNICAÇÃO E LINGUAGEM VISUAL}

A comunicação humana se dá por meio de uma infinidade de signos, que podem ser constituídos de palavras, imagens, sons, cheiros, gestos. Embora as diferentes linguagens se complementem, 
considera-se que a visual seja a mais universal, porque supera as diferenças impostas pelas diversas línguas, de modo que uma imagem, diferentemente de uma palavra, pode ser compreendida por indivíduos de países distintos. Soma-se a isto o fato de atualmente o indivíduo se encontrar num mundo impregnado de imagens a serem decodificadas, seja na televisão, na internet, no cinema e na publicidade.

Contudo, a linguagem visual, mesmo sendo de fácil reprodução e de maior possibilidade de compreensão, se comparada à linguagem verbal, para ser eficaz necessita de "planejamento", intencionalidade. Isto é possível por meio do conhecimento e da aplicação de seus princípios e componentes básicos. Esses componentes, em obras de natureza não verbal, se constituem na unidade mínima das imagens, possuindo capacidade para expressar um grande número de ideias. Tal como as palavras em um texto, eles precisam estar estrategicamente organizados e relacionados entre si, formando um todo coerente, capaz de transmitir uma mensagem clara e efetiva.

Em relação a estes elementos, Dondis (1997) aponta a linha, o ponto, a forma, a direção, o tom, a cor, a textura, a proporção, a dimensão e o movimento. Juntos, eles se constituem no conteúdo visual da obra, interagindo entre si e comunicando de forma complexa ideias e intenções. Conhecer estes elementos visuais e seus significados permite uma análise e compreensão da estrutura total de uma linguagem visual.

Dentre estes elementos, a cor exerce uma grande influência na mensagem, por ser rapidamente identificável. A partir disso, entende-se que ela, por si só, transmite informação, pois o "homem reage a ela subordinado às suas condições físicas e às suas influências culturais" (FARINA, 1990, p.27). Acrescenta-se a isso o fato de ela possuir afinidades com as emoções, evocando sensações e sentidos.

Wechsler (2002) afirma que a cor "pode aumentar a atenção e a percepção do realismo nas ilustrações" (p.13). O que sinaliza a importância da cor na comunicação visual, pela sua grande capacidade de atrair a atenção ao produzir vibração psíquica. Em relação a isto, Guimarães (2004) alerta para o fato de que a transmissão da cor interfere e sofre influência no processo de comunicação humana, pois ela é uma forma de informação cultural. O autor acredita na potencialidade da cor como informação, caracterizando-a como um código cultural.

Devido a isto, conhecer seu significado é importante para o entendimento da mensagem. A compreensão da linguagem visual não se dá apenas pelo conhecimento de seus elementos básicos, mas por uma análise da totalidade onde a obra está inserida, pois isto altera o modo como a imagem será percebida e determina uma forma de interação com a sociedade. Dentro do atual cenário capitalista, tanto a publicidade como a propaganda se utilizam da linguagem visual, numa tentativa de persuadir o público em relação a determinadas ideias (GOMES, 2001). Deste modo, é importante contextualizar os significados dos elementos visuais, com os dispositivos que lhe dão suporte. 
As mídias exteriores, também conhecidas por mídia ao ar livre ou publicidade externa, são materiais publicitários que se utilizam da comunicação visual para veicular ideias e promover imagens corporativas a partir dos meios de comunicação de massa. Essas veiculações possuem vários formatos, sendo os mais comuns: outdoor, frontlight, backlight, totem, fachada, cartaz, painel digital, busdoor, relógio, projeção, galhardete, placa de rua, triedro. Embora essas mídias, em sua gênese, assumem a função de dar visibilidade à mensagem, os discursos podem assumir outros significados a depender do posicionamento, da quantidade, do suporte e do local onde essas mídias se encontram. Apesar de possuir uma mesma função, cada mídia apresenta características que a distingue uma da outra. Isso implica, inclusive, nos efeitos negativos que a comunicação visual pode provocar, uma delas elemento de análise desse estudo - é a produção de ruído, aqui entendido como uma enorme quantidade de anúncios que promovem um caos visual no cenário urbano.

Esse comprometimento estético é denominado poluição visual. As definições do termo são vastas, abrangendo desde o acúmulo exagerado de anúncios publicitários (MINAMI; GUIMARÃES, 2001) até o desequilíbrio do espaço urbano (ANTACLI, 2004). Estes obstáculos à percepção dos espaços da cidade dificultam a orientação dos habitantes da paisagem urbana. $\mathrm{O}$ termo paisagem urbana é utilizado com o sentido da "roupagem com que as cidades se apresentam a seus habitantes e visitantes" (Direito Urbanístico Brasileiro citado em Castanheiro, 2009, p.65). Ou seja, trata-se do meio ambiente natural e artificial (construído), de todos os espaços habitados dentro do que se considera cidade.

A questão da poluição visual vai além dos padrões estéticos, pois ela agride o ambiente de vida das pessoas, ocasionando a dificuldade de percepção dos espaços na cidade. Castanheiro (2009) alerta que a publicidade se torna um problema a partir do momento em que "o meio não consegue mais digerir os elementos causadores das transformações em curso, dissipando as características naturais originais" (p.65).

Espaços públicos ficam cada vez mais difíceis de serem percebidos como tal, dada a publicidade circundante que os 'escondem', e que muda em pequenos intervalos de tempo, dificultando a formação de uma referência. Essa situação prejudica demasiadamente a unidade do local, e o processo de identificação do homem com o espaço que habita. Diversas capitais brasileiras enfrentam a problemática da poluição visual, muitas vezes com a atividade comercial contribuindo também para a degradação de centros históricos (LEITE, 2020; ANDRADE, 2021).

Extrapolando a questão cultural, a poluição visual é responsável pela ameaça a "saúde, a segurança e o bem-estar da população” (JORGE; GENTIL, 2009, p. 57). Aqui o termo saúde é entendido a partir de uma concepção global, postulado pela Organização Mundial de Saúde (OMS), que o define como um bem-estar físico, mental e social e não apenas a ausência de doenças ou danos. 
Assim, a poluição visual traz danos à saúde na medida em que impede o bem-estar dos habitantes do espaço urbano.

Diversos estudos comprovam que a poluição visual causa danos à saúde uma vez que provoca fadiga visual. Oliveira (2003) afirma que o excesso de informação visual causa fadiga e que esta se constitui na "saturação de um organismo devido ao esforço, ou como perda temporária da capacidade de resposta ou reação devido a uma estimulação contínua" (p.29). Dessa forma, a fadiga seria uma consequência fisiológica decorrente da contração excessiva dos músculos oculares em resposta a um ambiente poluído visualmente, que pode levar ao estresse, com "sintomas visuais (cansaço nas vistas, redução da acuidade visual, lacrimejamento) e musculares (dor no pescoço e ombros e dor nas costas)" (ROCHA; DEBERT-RIBEIRO, 2001, p.544), além de sensação de queimação nos olhos, dores de cabeça, visão embaçada, entre outros.

Estudos realizados por Pinheiro (2004) apontam que indivíduos expostos a poluição visual, apresentam consequências psíquicas que vão além da fadiga. Quando solicitados a mencionar o que sentiam ante um ambiente com excesso de informações, os indivíduos sinalizaram: "dispersão da atenção, [...], mistura de informações, irritação, lapsos de memória, falta de organização, ansiedade, inquietação visual, [...] e confusão" (PINHEIRO, 2004, p.2). A partir dos resultados deste estudo, percebemos que vários processos cognitivos são prejudicados devido à poluição visual, que além de causar agressões estéticas ao ambiente e danos psicofísicos aos indivíduos que habitam as cidades, interfere também na mobilidade dos condutores de veículos. Em muitas situações, a publicidade pode provocar distração nos motoristas, comprometendo a visualização da sinalização de trânsito ou distraindo o condutor em relação ao traçado da via (CASTANHEIRO, 2009).

O acúmulo de material publicitário atrai a atenção dos motoristas e pedestres, dificultando a absorção de informações necessárias ao deslocamento, aumentando a probabilidade de acidentes. $\mathrm{O}$ que nos permitiu fazer a leitura de que se trata de uma questão tangencial a toda a população, demandando responsabilidade por parte de vários segmentos sociais. Contudo, é de competência do poder público o controle e a fiscalização da poluição visual.

As relações entre esses conceitos e as ações dele decorrentes se dão através de vários meios, um deles é a legislação. No Brasil a questão da poluição visual é tratada em muitos dispositivos legais, sobretudo na Constituição Federal e no Código de Trânsito. O artigo 225 da Constituição Federal, que trata do Meio Ambiente, postula que "todos têm direito ao meio ambiente ecologicamente equilibrado, bem de uso comum do povo e essencial à sadia qualidade de vida, impondo-se ao poder público e à coletividade o dever de defendê-lo e preservá-lo para as presentes e futuras gerações (BRASIL, 1988, p.143). 
No artigo referido, o uso da palavra meio ambiente é feito de forma ampla, incluindo o espaço urbano, modificado pelo homem. A questão da poluição visual está aí incluída e prevista no parágrafo 1, inciso IV que exige um estudo de impacto ambiental para a instalação de obra ou atividade publicitária possivelmente causadora de degradação do espaço urbano. O artigo 182, “caput”, aponta o bem-estar dos habitantes das cidades como um dos objetivos da política urbana.

A partir dessas observações, fica claro que a Constituição Federal oferece total amparo a proteção do meio ambiente urbano, nomeado de paisagem. Isto confere aos "habitantes e visitantes das cidades [...] o direito difuso a um meio ambiente ecologicamente equilibrado" (CASTANHEIRO, 2009, p.64). A garantia desse direito cabe aos entes federados, responsáveis por fiscalizar o cumprimento das normas relativas à harmonia da paisagem urbana.

Outro documento jurídico, o Código de Trânsito Brasileiro (Lei nº 9.503/98) aborda a questão da poluição visual. Os artigos 81, 82, 83 e 84 limitam o uso de elementos publicitários ou de outra natureza no perímetro urbano, de modo que não dificultem a livre circulação e segurança de pedestres e condutores. O artigo 81 é enfático ao proibir "luzes, publicidade, inscrições, vegetação e mobiliário que possam gerar confusão, interferir na visibilidade da sinalização e comprometer a segurança do trânsito.” (BRASIL, 2009, p.36). Trata-se de uma questão complexa, pois se estende para além da publicidade, e relaciona-se com o planejamento urbano e a fiscalização por parte do poder público.

Como pode ser observado, esta temática tem caráter multidisciplinar, envolvendo conhecimentos oriundos de várias áreas do saber, como Jornalismo, Publicidade e Propaganda, Psicologia, Engenharia de Trânsito, Arquitetura e Direito.

\section{CENÁRIO DA PESQUISA}

Palmas, a capital do Tocantins, foi fundada em 1989 e que foi concebida para ser numa cidade planejada, possuindo um Plano Diretor Urbanístico. O plano diretor é dividido em região Sul e região Norte e dividido em quadras, cada uma com 16 quarteirões em média, como se fossem mini-bairros. As quadras seguem um sistema de numeração, com números pares na porção leste e ímpares no lado oeste, tendo a Avenida Teotônio Segurado e a Avenida JK como divisores leste-oeste e norte-sul, respectivamente. E a Praça dos Girassóis como centro desse plano cartesiano, com o palácio do governo e as secretarias estaduais.

No entanto, o planejamento inicial não foi cumprido em sua totalidade e o poder público não conseguiu promover a ocupação ordenada e sequenciada por etapas ao longo dos 30 anos de povoamento da cidade. Diversas questões levaram a ocupação desordenada em algumas localidades do espaço urbano, gerando grandes vazios urbanos nas regiões centrais e agrupamentos confusos e densamente concentrados nas regiões periféricas (CORIOLANO et al, 2013). De modo que a 
população de menor poder aquisitivo se localiza em áreas em que o planejamento urbanístico não se efetivou a contento.

Devido a isso, Palmas-TO possui um centro simbólico e dois centros populares. Aqui consideramos centro não apenas um espaço de grande concentração de estabelecimentos comerciais, mas também troca de experiências e apropriação, além do sentimento de pertencimento dos moradores com a área (SANTOS et al., 2015). O centro projetado (simbólico) foi delimitado pelo plano diretor da cidade está localizado próximo a sede administrativa estadual (Praça dos Girassóis) (quadras 104 Norte e Sul). Já os centros populares estão nas Arnos (quadras de número ímpar na região Norte) e na Palmas Sul (Avenida Tocantins em Taquaralto) resultado da construção coletiva e da apropriação pela população. Estes últimos marcados pela ocupação de uma parcela menos favorecida da população.

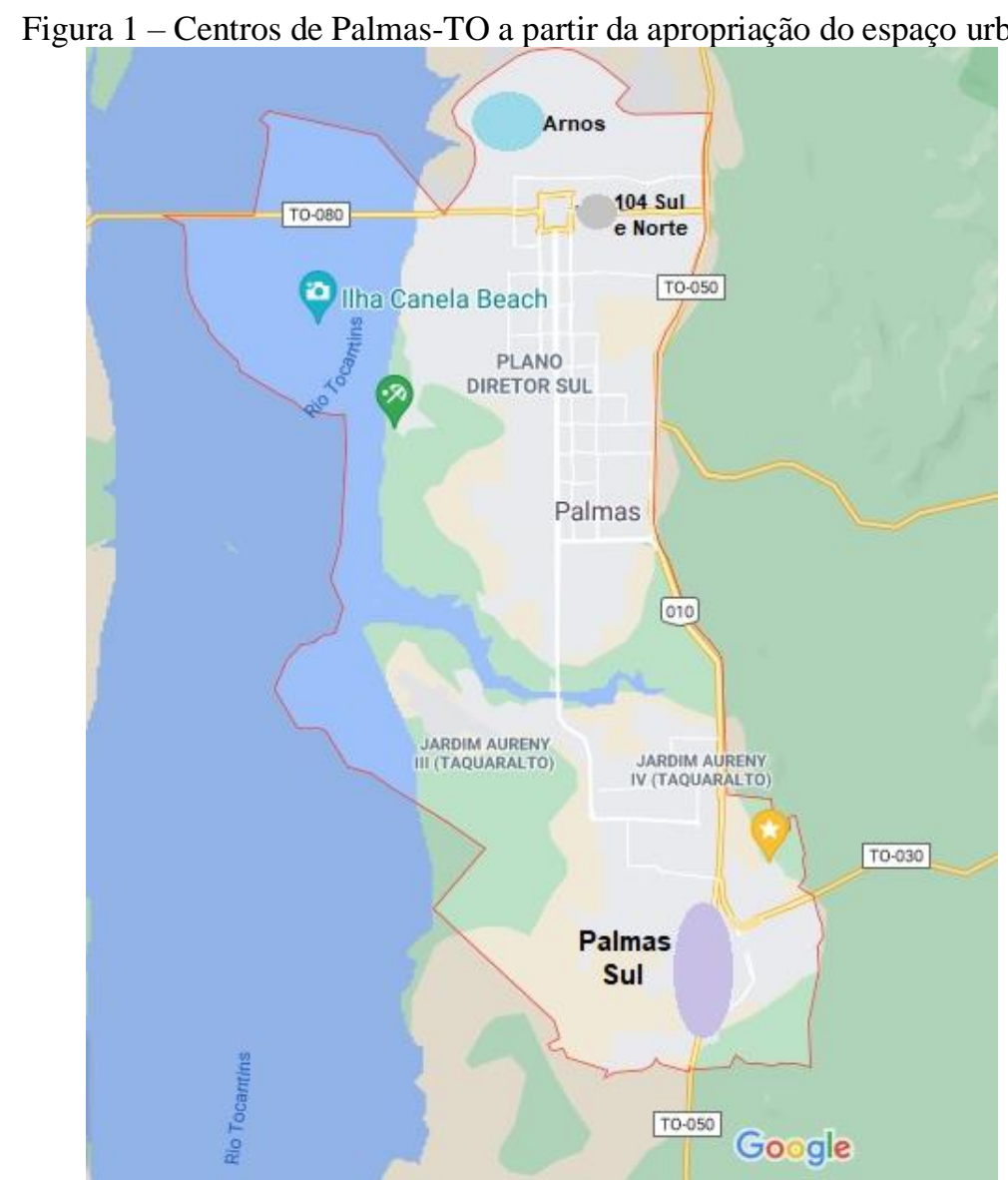

Fonte: elaborado pelas autoras a partir de imagem do Google Maps, 2021.

O centro simbólico e áreas próximas concentra muitos estabelecimentos comerciais e conta com uma grande circulação de pessoas. Devido a isso, é alvo de diversas instalações publicitárias, que visam atrair a atenção do consumidor. Em 2010 esta área continha muitos outdoors sobrepostos, alguns deles de madeira, em desacordo com a legislação vigente. As cores predominantes eram o azul, vermelho e branco e a imagem fotográfica era utilizada nas peças publicitárias como principal argumento da 
mensagem que se gostaria de transmitir (CECCHIN \& TEIXEIRA, 2017). A propaganda política havia sido inserida em pequenas placas abaixo dos outdoors, gerando um contexto de grave poluição visual, dificultando a percepção da mensagem pelos observadores (CECCHIN \& TEIXEIRA, 2012). Por limitações de tempo e equipe, a pesquisa citada se restringiu ao centro simbólico e áreas de influência.

Tendo isso em vista, o objetivo dessa pesquisa foi de mapear a poluição visual, no espaço urbano, em Palmas-TO e comparar com a poluição visual existente em 2010. Para permitir a comparação com os dados anteriores, manteve-se a mesmas quadras monitoradas: 101 Norte, 101 Sul, 103 Norte, 104 Norte, 105 Sul, 106 Norte, 201 Norte, 201 Sul, 301 Sul e 401 Sul. Nas duas coletas as fotos foram realizadas por um pesquisador no período vespertino, entre $13 \mathrm{~h}$ e $16 \mathrm{~h}$, horário em que a luz solar iluminava esses painéis.

\section{EM MAIS DE UMA DÉCADA, QUAIS AS MUDANÇAS NO ESPAÇO URBANO?}

Em franca expansão, Palmas possui um crescimento econômico e demográfico que supera a porcentagem do resto do país. No entanto, apesar de ser uma cidade planejada e recente, se comparada com outras capitais brasileiras, ela apresenta muitos pontos em que há poluição visual. Contudo, a comparação dos registros fotográficos de 2010 e 2021 demonstrou uma diminuição da quantidade de outdoors nas áreas monitoradas a partir de uma atuação da gestão municipal.

Em 2010 muitos outdoors eram de madeira, em situação irregular, desrespeitando a Lei Municipal 371/92, (Código de Posturas de Palmas), que desde 2008 proíbe este tipo de outdoor. Além de prejudicar o paisagismo urbano, ele oferece risco à população, já que a maioria apodrece com o tempo, ficando suscetível a ventos fortes que podem derrubá-lo e causar acidentes. Ao longo do tempo esses outdoors foram retirados pelo poder público (Conexão Tocantins, 2014), talvez por influência das mobilizações em torno da Lei Cidade Limpa em São Paulo que repercutiu em diversas capitais brasileiras. O registro fotográfico de 2021 demonstrou que todos os outdoors de madeira foram retirados, como pode ser visto na imagem a seguir. 

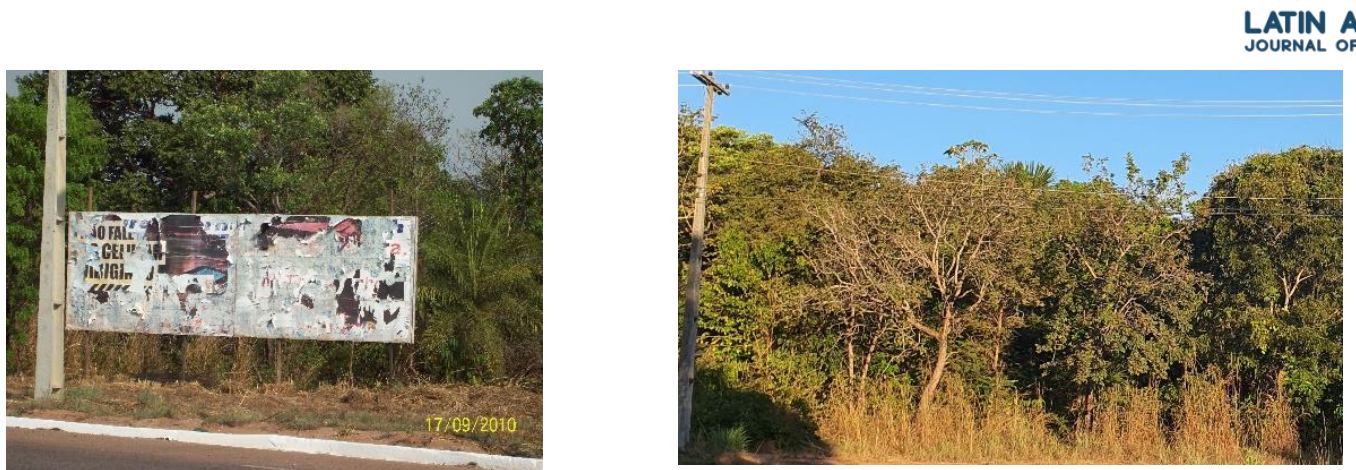

Fonte: banco de dados da pesquisa.

Registrou-se também a retirada de alguns outdoors de metal, como pode ser visto nas figuras 4 e 5. A retirada dos outdoors contribuíram também para uma maior visualização da vegetação natural. A preservação das árvores também contribui para a harmonia da paisagem, quebrando a rigidez do concreto, criando linhas mais suaves, além de atenuar a poluição visual, delimitando espaços, caracterizando paisagens e orientando visualmente os vários componentes do contexto (BITTENCOURT, 2020).
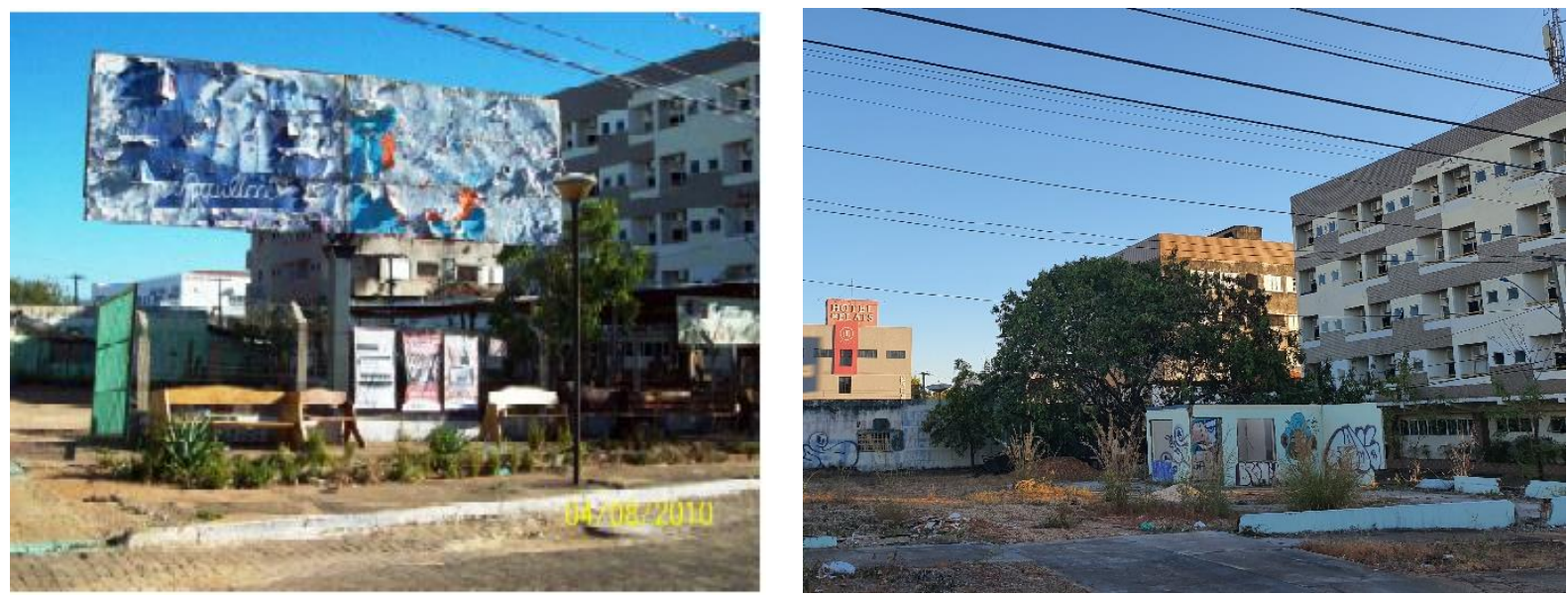

Fonte: banco de dados da pesquisa.

Houve diminuição dos conteúdos publicitários nas imediações do Shopping Capim Dourado, seguindo tendência contrária a 2010, época em que havia um aumento progressivo de instalações (CECCHIN \& TEIXEIRA, 2012). Isso é um avanço que deve ser destacado porque, para conseguir perceber tantos elementos ao mesmo tempo, os motoristas precisam dispender mais tempo de percepção, podendo tomar sua atenção por um tempo prolongado, contribuindo para os acidentes de trânsito. 


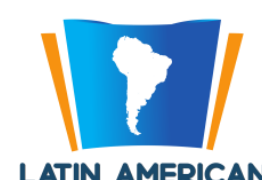

LATIN AMERICAN

Outra questão são as faixas e pequenas placas fixadas nos outdoors ou próximo deles, aumentando a carga visual do conjunto. Também foi observado a retirada dessas faixas e placas ao longo do tempo. Isso ocorreu não só na área próxima ao shopping, como também nas demais localidades monitoradas, como pode ser observado nas figuras $6 ; 7 ; 8$ e 9. Isso pode ser positivo não só para os consumidores das peças publicitárias, mas também para os anunciantes. Estudos apontam que é difícil capturar a atenção dos consumidores em ambiente de grande poluição visual e concorrência de vários anúncios, e que nessas condições algumas mídias externas sequer são notadas pelos consumidores (LEVRINI, 2020).

Figuras 6 e 7 - Acúmulo de outdoors, placas e faixas próximo ao shopping em 2010.
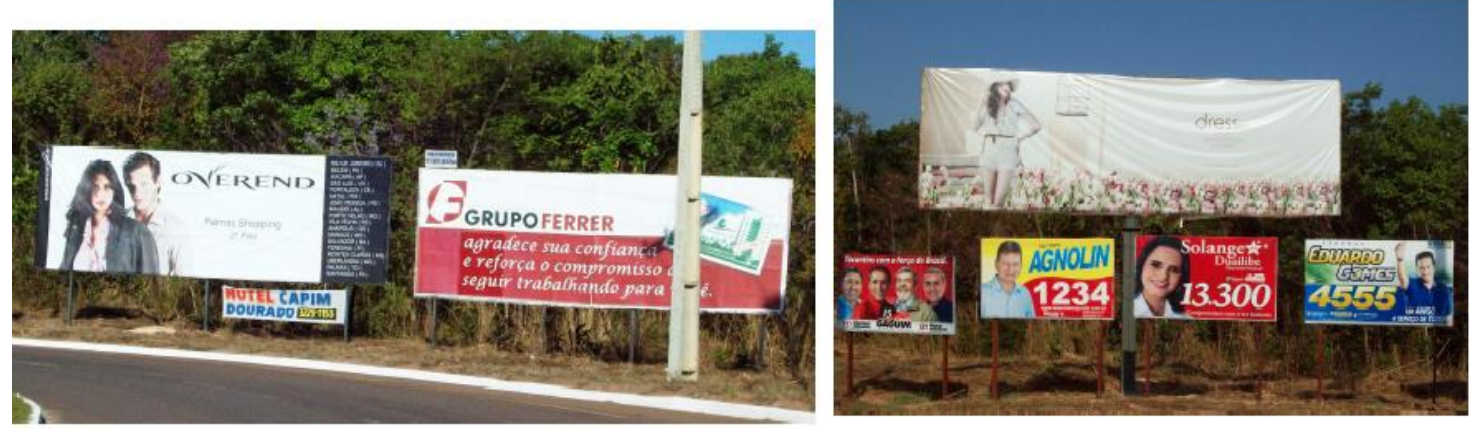

Fonte: banco de dados da pesquisa.

Figuras 8 e 9 - Redução do número de outdoors, placas e faixas na mesma área, em 2021.
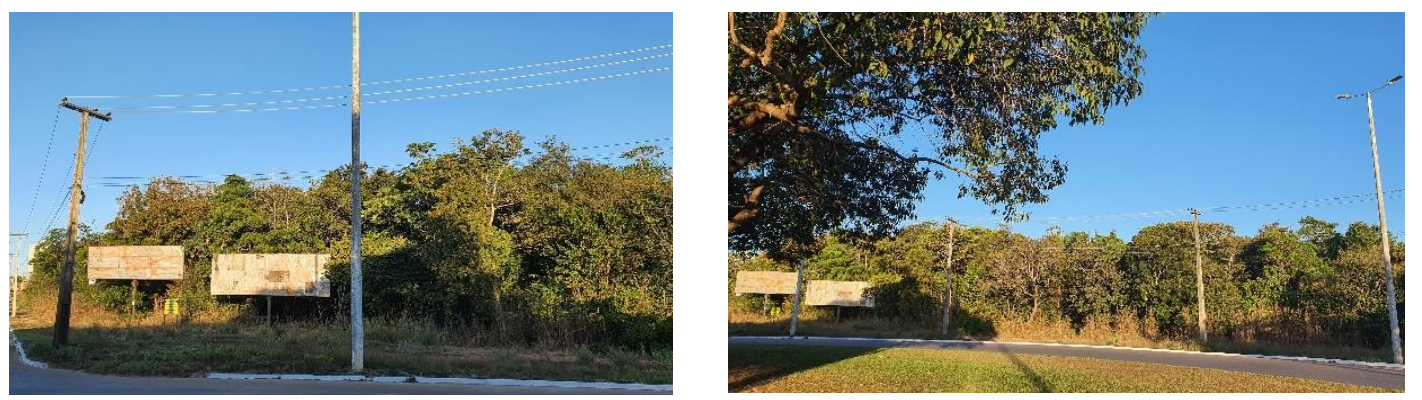

Fonte: banco de dados da pesquisa.

Destaca-se a presença de propaganda política das pequenas placas em desacordo com a legislação vigente que só permite outdoors de tamanho definido. Observa-se uma relação entre a mídia e a política partidária, uma vez que esta faz uso da mídia, em seus mais diferentes formatos, para defender seus interesses (FERNANDES \& CAMPOS, 2021). No entanto o poder público atuou no sentido de retirá-la da paisagem.

A comparação dos monitoramentos fotográficos demonstrou que os outdoors de metal sem anúncio é uma problemática ainda não resolvida na cidade. Isso é complicado porque além de perturbar a harmonia da paisagem urbana ao demonstrar uma imagem de depauperação, existe o efeito da ação 
do sol na placa de metal, que reflete a luz. Isso pode causar um desconforto na visão, podendo vir a configurar uma distração e/ou fadiga visual, levando o indivíduo a um desconforto psicológico que, neste trabalho, entende-se por consequência psíquica. 
Figura 10 - Outdoor de metal refletindo a luz do sol em 2010.

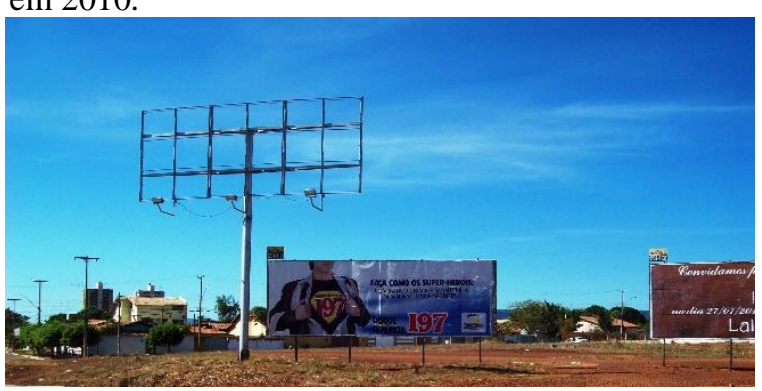

Figuras 11 - Outdoor de metal refletindo a luz do sol em 2021.

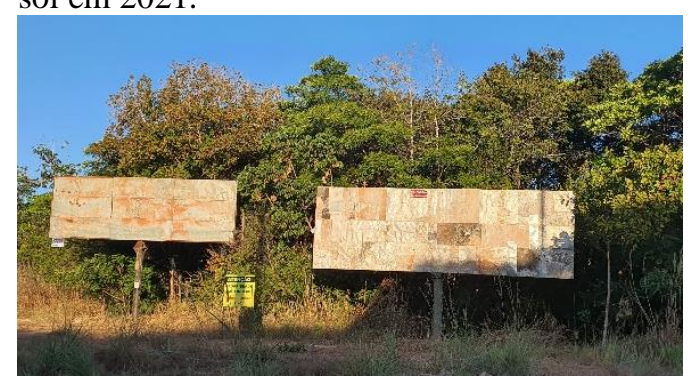

Fonte: banco de dados da pesquisa.

Isto denota não só uma poluição material e visual, como um desperdício de espaço, pois ao invés da instalação de novos outdoors, este poderia ser utilizado. É importante lembrar que a cidade é um "ambiente que se comunica como espaço social" (SOUZA, 2009, p.2), desse modo, um outdoor nesse estado passa uma imagem de desleixo, não só da publicidade de rua, como também do espaço urbano. Isso também se configura como poluição visual.

Em outra localidade, observou-se que o poder público conseguiu retirar os outdoors, mas a iniciativa privada incorporou a publicidade a sua estrutura predial. Isso denota como a cidade se torna um parque de especulação imobiliária, tendo seus espaços valorizados para grandes empresas, em detrimento do cidadão e da experiência que ele pode ter, seja de conforto ou de vazio (ANDRADE, 2021).

Figuras 12, 13 e 14 - Outdoors em lote na quadra 104 Norte em 2010.
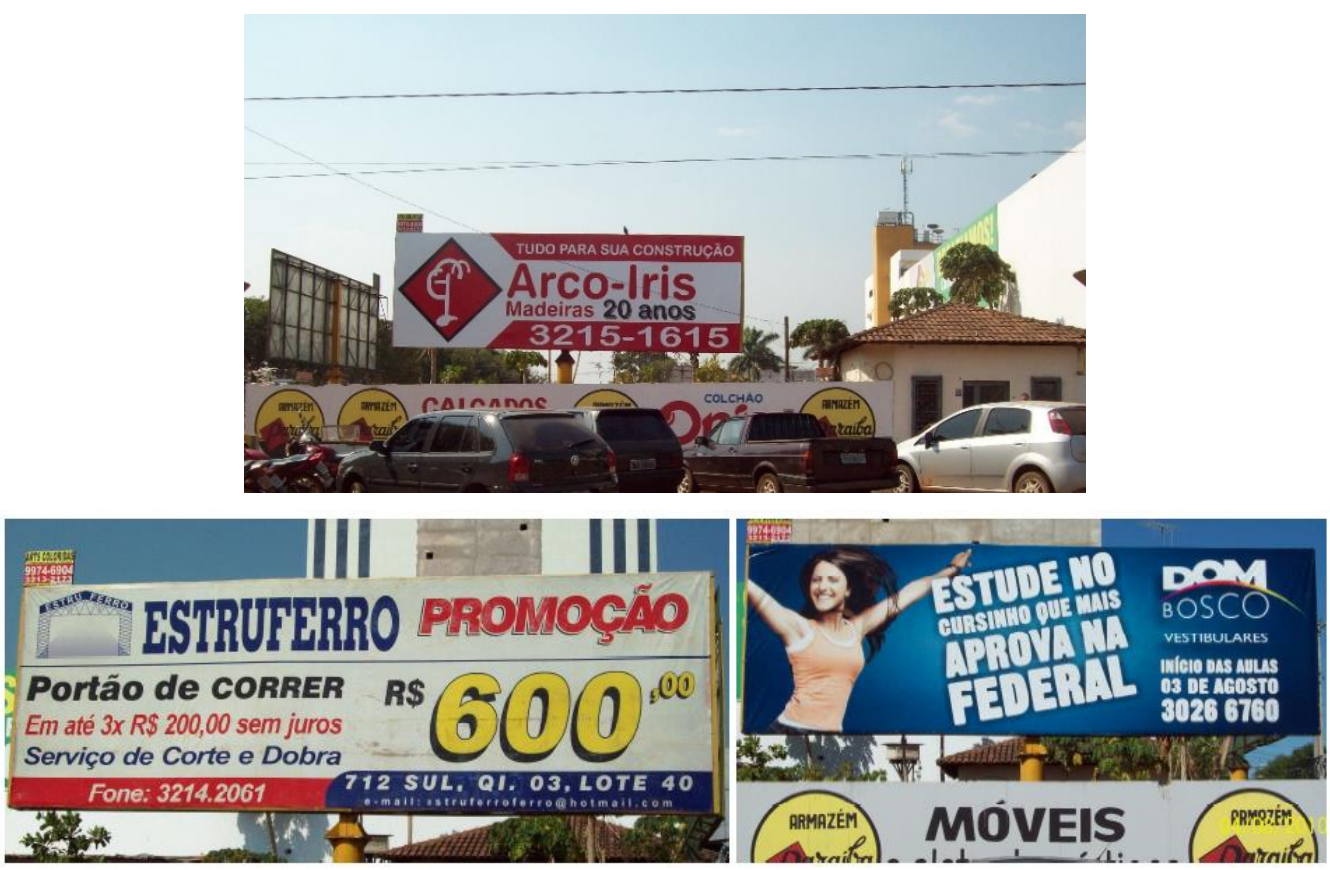

Fonte: banco de dados da pesquisa. 
Figuras 11 - Outdoors incorporados a estrutura predial na quadra 104 Norte em 2021.
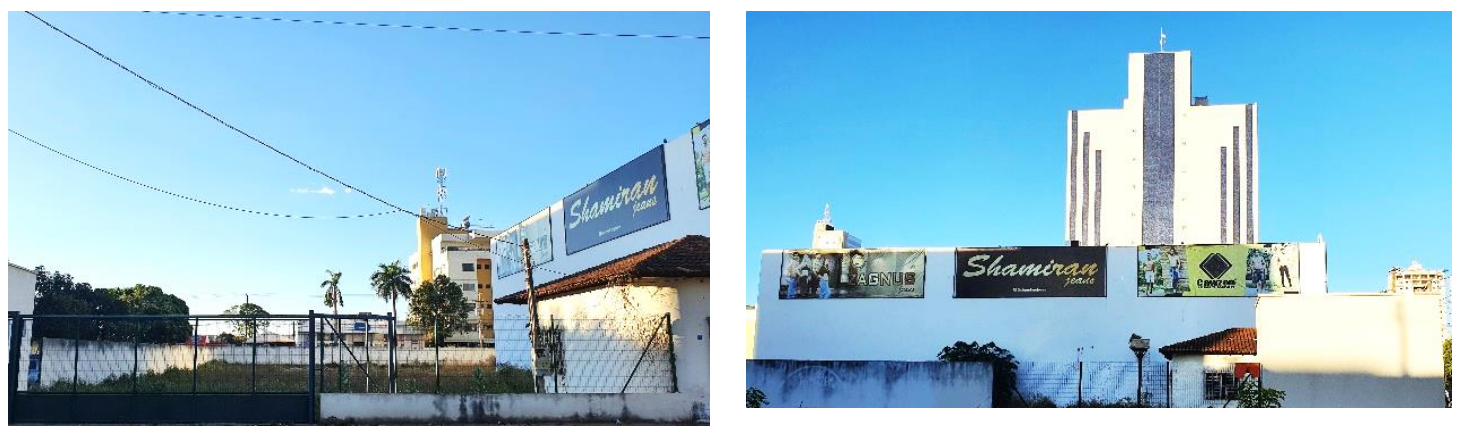

Fonte: banco de dados da pesquisa.

Outro ponto a ser considerado é que em 2018 registrou-se uma diminuição do investimento em mídias tradicionais como TV (-7,2\%), mídia impressa (-17,6\%), radio (-4,2\%), e com um aumento de mídia mobile $(20,40 \%)$ e mídia externa $(2,5 \%)$, em função do aumento de compras pela internet, sobretudo pelo celular (EMARKETER, 2019). No entanto, o tipo de mídia externa que vem crescendo tem uma característica específica: a fusão com tecnologia digitais (conteúdo, dinâmica e luz) transformando os outdoors em painéis digitais (LEVRINI, 2020). Não foram encontrados painéis digitais nas localidades monitoradas, porém a cidade conta com alguns destes em alguns pontos da cidade.

\section{CONSIDERAÇÕES}

A poluição visual é um fenômeno que compromete a paisagem urbana, e está diretamente relacionado ao crescimento das cidades. Dessa forma, o estudo possibilitou observar que outdoors de madeira, pequenas placas e faixas foram retiradas. Alguns outdoors de metal também foram retirados. Em algumas localidades onde o poder público conseguiu retirar os outdoors, a iniciativa privada incorporou a publicidade a sua estrutura predial. Os outdoors de metal sem anúncio é uma problemática ainda não resolvida na cidade. Não foram encontrados painéis digitais nas localidades monitoradas, porém a cidade conta com alguns destes em alguns pontos da cidade. Não foram encontrados outdoors em situação irregular, demonstrando maior planejamento e fiscalização por parte dos órgãos públicos.

A poluição visual é um fenômeno que deve ser discutido em políticas públicas, visto que afeta diretamente a qualidade de vida do indivíduo, o bem-estar, a paisagem urbana e a memória das cidades. A instalação de novos outdoors deve ser orientada por um estudo prévio, visto que enquanto houver outdoors disponíveis para abrigar a publicidade de rua, não devem ser autorizados a instalação de novas estruturas. Com isso, a poluição visual da cidade pode ser prevenida a partir da atuação do poder público que pode equilibrar a demanda do mercado publicitário e o planejamento urbanístico. 
Aos gestores públicos e a sociedade civil sugere-se o contínuo monitoramento da poluição visual. Este monitoramento pode se dar tanto por órgãos de fiscalização como por meio do apoio da sociedade civil, como a partir de concursos de fotografia. Isso pode fazer parte de uma política governamental que efetivada por meio de um projeto de documentação fotográfica das transformações paisagísticas urbanas de Palmas-TO, tais como realizado em outras cidades (BONI \& PONPOLIN, 2020). Além da poluição visual, seria de grande valia que outras transformações no espaço urbano fossem documentadas. tais como: a pavimentação de vias, a demolição de casas e estabelecimentos comerciais, a construção de prédios, pontes e praças, entre outros.

Como agenda de pesquisa, seria interessante que estudos futuros considerassem a influência da poluição visual nas ocorrências de acidentes de trânsito, uma vez que os elementos ligados à poluição visual podem levar à distração e fadiga visual. Estes acidentes podem trazer sérias consequências psíquicas para os envolvidos, como fobia de dirigir, depressão, estresse, entre outras. Os resultados deste estudo permitem uma reflexão do contexto histórico recente da cidade de Palmas-TO. Porém, sabe-se que os elementos aqui destacados são apenas alguns dos fatores a serem observados.

\section{DECLARAÇÃO DE INTERESSE}

A coleta de dados realizada em 2010 ocorreu como parte do projeto de pesquisa "A poluição visual por meio das cores no espaço urbano e as consequências psíquicas: um estudo de caso em Palmas-TO” financiado pelo Programa de Iniciação Científica e Tecnológica (PROICT), ao Centro Universitário Luterano de Palmas (Ceulp/Ulbra). A segunda coleta de dados, realizada em 2021, se deu pelo mesmo grupo de pesquisadoras, porém com financiamento próprio. As autoras declaram que nenhum conflito de interesse está envolvido no estudo. 


\section{REFERÊNCIAS}

ANDRADE, L. S. Intervenções urbanas artísticas efêmeras: alternativas de valorização do espaço urbano no bairro centro de Aracaju-SE. Caderno de Graduação - Ciências Humanas e Sociais UNIT - SERGIPE, [S. l.], v. 6, n. 3, p. 41, 2021. Disponível em: https://periodicos.set.edu.br/cadernohumanas/article/view/9599. Acesso em: 8 jul. 2021.

ANTACLI, B. M. B. S. Aspectos jurídicos da poluição visual. Dissertação (Mestrado em Direito Difusos e Coletivos). Pontifícia Universidade Católica de São Paulo, São Paulo, 2004.

BRASIL. Código de Trânsito Brasileiro. Lei no .9 .503 de 23 de setembro de 1997. São Paulo: Saraiva, 2009.

BRASIL. Constituição (1988). Constituição da República Federativa do Brasil: texto constitucional promulgado em 5 de outubro de 1988, com as alterações adotadas pelas Emendas Constitucionais de Revisão no $1 / 92$ a 56/2007 e pelas Emendas Constitucionais de Revisão no 1 a 6/94. Brasília: Senado Federal, Subsecretaria de Edições Técnicas, 2008.

BRASIL. Ministério da Saúde. Mapeamento das Mortes por Acidentes de Trânsito no Brasil. 2009. Disponível em: http://observasaude.fundap.sp.gov.br/RgMetropolitana/AcidTransporte/Acervo/EstTransito.pdf Acesso em: 9 jan. 2021.

BITTENCOURT, C. R. Arborização das praças das quadras do plano diretor de Palmas-TO. Monografia. Curso de Engenharia Ambiental, Universidade Federal do Tocantins - UFT, 2020. Disponível em: <http://hdl.handle.net/11612/2336> Acesso em: 8 jul. 2021.

BONI, P. C.; POPOLIN, C. M. A história de Londrina contada por imagens: 20 anos de documentação fotográfica. p. 1-17. In: Antunes, A. F. (org.) Saberes tradicionais e conhecimentos científicos nas Ciências Humanas. Ponta Grossa - PR: Atena, 2020.

CASTANHEIRO, I. C. A poluição visual: formas de enfrentamento pelas cidades. Revista Internacional de Direito e Cidadania, n. 4, p. 63-78, junho/2009.

CECCHIN, H. F. G.; TEIXEIRA, I. A poluição visual e seus impactos no espaço urbano: um estudo de caso em Palmas-TO. Anais do XXXV Congresso Brasileiro de Ciências da Comunicação, 2012, Fortaleza. Disponível em: http://www.intercom.org.br/papers/nacionais/2012/resumos/R7-2295-1.pdf Acesso em: 6 jul. 2021.

CECCHIN, H. F. G.; TEIXEIRA, I. Um olhar para a paisagem urbana em Palmas-TO: reflexões sobre a comunicação visual e seus efeitos. In: Ward, Rodolfo (org.). Narrativas e representatividades, a interdisciplinaridade na Comunicação. Palmas-TO, Universidade Federal do Tocantins, EDUFT, 2017.

Conexão Tocantins. Prefeitura intensifica fiscalização contra poluição visual. Redação, PalmasTO, 2014. Disponível em:

https://conexaoto.com.br/2014/04/16/prefeitura-intensifica-fiscalizacao-contra-poluicao-visual-extraja-foi-notificado-duas-vezes Acesso em: 6 jul. 2021. 
CORIOLANO, G. P., RODRIGUES, W. e OLIVEIRA, A. F. Estatuto da Cidade e seus instrumentos de combate às desigualdades socioterritoriais: o Plano Diretor Participativo de Palmas (TO). Urbe Revista Brasileira de Gestão Urbana [online]. 2013, v. 5, n. 2 [Acessado 6 Julho 2021], pp. 131-145. Disponível em: <https://doi.org/10.7213/urbe.05.002.AC04>. Acesso em: 6 jul. 2021.

DONDIS, D. A. Sintaxe da Linguagem visual. Trad. Jefferson Luiz Camargo. $2^{\mathrm{a}}$ ed. São Paulo: Martins Fontes, 1997.

Emarketer. US Social Trends for 2019. 2019 Disponível em: https://www.emarketer.com/content/ussocial-trends-for-2019 . Acesso em: 6 jul. 2021.

FARINA, M. Psicodinâmica das cores em comunicação. 4ª ed. São Paulo: Edgar Blücher, 1990.

FERNANDA, L. Palmas é a capital com trânsito mais inseguro em todo País. Jornal do Tocantins, Palmas, 2019. Disponível em: https://www.jornaldotocantins.com.br/editorias/vida-urbana/palmas\%C3\%A9-a-capital-com-tr\%C3\%A2nsito-mais-inseguro-em-todo-pa\%C3\%ADs-1.1949707 Acesso em: 6 jul. 2021.

FERNANDES, J. M.; CAMPOS JR, L. D. C. Mídia e sua influência na sociedade e na política brasileira do século XXI. Latin American Journal of Development, v. 3, n. 3, p. 1295-1300, 4 Jun. 2021. Disponível em: https://latinamericanpublicacoes.com.br/ojs/index.php/jdev/article/view/340 Acesso em: 8 jul. 2021.

GOMES, N. D. Publicidade ou Propaganda? É isso aí! Revista FAMECOS, Porto Alegre, $\mathrm{n}^{\circ}$ 16, dezembro, 2001, quadrimestral. $\quad$ Disponível em <http://revistaseletronicas.pucrs.br/ojs/index.php/revistafamecos/article/viewFile/3142/2413>. Acesso em: 19 jan. 2021.

GUIMARÃES, L. A cor como informação: a construção biofísica, linguística e cultural da simbologia das cores. $3^{\text {a }}$ ed. São Paulo: Annablume, 2004.

JORGE, A. P.; GENTIL, P. A. B. Função social da propriedade: a problemática da poluição visual. Revista SJRJ, Rio de Janeiro, n.25, p.47-61, 2009. Disponível em:

<http://www4.jfrj.jus.br/seer/index.php/revista_sjrj/article/view/7>. Acesso em: 9 jan. 2021.

LEITE, B. S. A. Poluição visual: um olhar sobre a face oculta do centro de Goiânia. Trabalho de Conclusão de Curso. Curso de Jornalismo. Pontifícia Universidade Católica de Goiás, 2020. Disponível em < https://repositorio.pucgoias.edu.br/jspui/handle/123456789/557> Acesso em: 7 jul. 2021.

LEVRINI, G. A utilização do eye-tracker como ferramenta auxiliar para aumento da eficácia na visualização das mídias externas tradicionais (OOH). Marketing \& Tourism Review, [S. 1.], v. 5, n. 2, 2021. DOI: 10.29149/mtr.v5i1.5765. Disponível em: https://revistas.face.ufmg.br/index.php/mtr/article/view/5765. Acesso em: 8 jul. 2021.

MINAMI, I., GUIMARÃES, J. L. Jr. A importância da Paisagem. Revista Arquitetos, ano 2, agosto, 2001. ISSN: 1809-6298. Disponível em <http://www.vitruvius.com.br/arquitextos/arq000/bases/texto094.asp> Acesso em: 19 jan. 2021. 
OLIVEIRA, L. P. Determinação de parâmetros para avaliação da poluição visual urbana. Dissertação, (Mestrado em Arquitetura), 2003. Universidade Federal de Brasília, UNB, Brasília. Disponível em <https://repositorio.bce.unb.br/handle/10482/5482> Acesso em: 18 mar. 2021.

PEREIRA, D. Palmas é a $7^{\mathrm{a}}$ capital com menor índice de acidentes de trânsito. Jornal do Tocantins, 2018. Disponível em: https://www.jornaldotocantins.com.br/editorias/vida-urbana/palmas- \%C3\%A9a-7\%C2\%AA-capital-com-menor-\%C3\%ADndice-de-acidentes-de-tr\%C3\%A2nsito-1.1693399 Acessado em 06 jul. 2021.

PINHEIRO, A. C. P. Poluição visual no Campus da Universidade de Brasília. Laboratório de Psicologia Ambiental. Série: Textos de alunos de Psicologia Ambiental, 2004, $\mathrm{n}^{\circ} 2$. Universidade de Brasília, Instituto de Psicologia. Disponível em: http://www.psiambiental.net/pdf/2004poluicao.pdf Acesso em: 18 mar. 2021.

ROCHA, Lys Esther; DEBERT-RIBEIRO, Myriam. Trabalho, saúde e gênero: estudo comparativo sobre analistas de sistemas. Rev Saúde Pública, USP, 2001; 35(6), p.539-547. Disponível em <http://www.scielo.br/pdf/rsp/v35n6/7066.pdf>. Acesso em: 30 mar. 2021

SANTOS, A. L.; OLIVEIRA, L. A.; PEREIRA, O. C. M. A apropriação do espaço e a construção simbólica - os centros de Palmas - TO. Anais do III Encontro da Associação Nacional de Pesquisa e Pós-graduação em Arquitetura e Urbanismo "Arquitetura, cidade e projeto: uma construção coletiva". São Paulo, 2014.

SOUZA, L. C. Eros cindido: representação nos outdoors de São Paulo antes da lei "Cidade Limpa". Revista da Associação Nacional dos Programas de Pós-Graduação em Comunicação - E-compós, Brasília, v.12, n.1, jan./abr. 2009. Disponível em <http://www.compos.org.br/seer/index.php/ecompos/article/view/287> Acesso em: 20 mar. 2021.

WECHSLER, D. WISC-III: Escala de Inteligência de Wechsler para Crianças. Manual. $3^{\mathrm{a}}$ ed. Adaptação e Padronização da amostra brasileira: Vera Lúcia Marques de Figueiredo. São Paulo: Casa do Psicólogo, 2002. 